\title{
UMA APLICAÇÃO DA ANÁLISE DE IMAGENS NA CARACTERIZAÇÃO MICROESTRUTURAL DE CERÂMICAS VARISTORAS
}

\author{
José Geraldo de Melo Furtado ' \\ Rodrigo Dias ${ }^{2}$ \\ Maria Cecília de Souza Nóbrega ${ }^{3}$ \\ Eduardo Torres Serra ${ }^{4}$
}

\section{Resumo}

Varistores são complexos sistemas cerâmicos policristalinos contendo diversos dopantes e suas propriedades elétricas são diretamente dependentes da composição química e das características microestruturais, tais como tamanho de grão, porosidade, maclas e distribuição de fases. O objetivo deste trabalho é avaliar, usando métodos de análise de imagens, as características microestruturais das cerâmicas varistoras. A caracterização microestrutural foi feita por microscopia eletrônica de varredura e espectroscopia de raios-X por dispersão de energia. Parâmetros microestruturais e morfológicos foram obtidos por técnicas de análise de imagens baseadas no uso de filtros apropriados. Métodos de segmentação e binarização foram usados para diferenciar propriedades dos grãos e dos contornos de grão, bem como a presença de fases secundárias, proporcionando a obtenção de informações estruturais e morfológicas. Determinou-se a influência do teor de material formador de camadas intergranulares sobre o grau de densificação, espessura média das camadas intergranulares e percentual médio de área das fotomicrografias ocupado por fases secundárias, para o caso de varistores à base de óxido de zinco dopados com óxidos de terras-raras.

Palavras-chave: Cerâmica varistora; Análise de imagem; Caracterização microestrutural.

\section{AN IMAGE ANALYSIS APPLICATION TO MICROSTRUCTURAL CHARACTERIZATION OF VARISTOR CERAMICS}

\begin{abstract}
Varistors are very complex polycrystalline ceramic systems containing several dopants and their electrical properties are directly dependent on the chemical composition and on microstructural characteristics, such as grain size, porosity, twins and phase distribution. The aim of this work is to evaluate, using image analysis tools, the microstructural characteristics of varistor ceramics. The microstructural characterization was made by scanning electron microscopy and energy dispersive $\mathrm{X}$-ray spectroscopy. Microstructural and morphological parameters were obtained by means image analysis techniques based on appropriate filters. Segmentation and binarization methods were used to differentiate grain and grain boundaries properties, as well phase structures. In this study, image processing and measurements have been developed in order to extract the relevant microstructural parameters on the varistor ceramics. It was developed an appropriate filtering and segmentation method for analysis of varistor ceramics to obtain grain and grain boundaries structural and morphological informations. In the case of zinc oxide-based varistors doped with rare-earth oxides it was determined the influence of the intergranular layer former material on the densification degree, the average thickness of the intergranular layers and the average percentage of area occupied by secondary phases.
\end{abstract}

Key words: Varistor ceramic; Image analysis; Microstructural characterization.

\footnotetext{
'D.Sc., Pesquisador, Departamento de Tecnologias Especiais, Centro de Pesquisa de Energia Elétrica - CEPEL/ELETROBRAS, CP 68007, Cep 21940-970, Rio de Janeiro, RJ, Brasil. E-mail: furtado@cepel.br

${ }^{2}$ Técnico Sênior, Departamento de Tecnologias Especiais, Centro de Pesquisa de Energia Elétrica - CEPEL/ELETROBRAS, CP 68007, Cep 21940-970, Rio de Janeiro, RJ, Brasil. E-mail: rodrigodias@cepel.br

${ }^{3}$ D.Sc., Professor, Departamento de Engenharia Metalúrgica e de Materiais, Universidade Federal do Rio de Janeiro - COPPE/UFRJ, CP 6850I, Cep 21945-970, Ilha do Fundão, Rio de Janeiro, RJ, Brasil. E-mail:mnobr@metalmat.ufri.br

${ }^{4}$ D.Sc., Pesquisador-consultor, Diretoria Geral, Centro de Pesquisa de Energia Elétrica - CEPEL/ELETROBRAS, CP 68007, Cep 21940-970, Rio de Janeiro, RJ, Brasil. E-mail: etserra@cepel.br
} 


\section{INTRODUÇÃO}

Varistores à base de óxido de zinco $(\mathrm{ZnO})$ são dispositivos cerâmicos que apresentam um comportamento elétrico caracterizado pela relação não-linear entre a tensão aplicada e a corrente elétrica resultante, bem como elevada capacidade de absorção de energia. ${ }^{(1,2)}$ A fabricação industrial destes dispositivos é feita a partir da mistura e homogeneização dos pós de $\mathrm{ZnO}$ e outros óxidos metálicos que atuam como dopantes, tais como $\mathrm{Bi}_{2} \mathrm{O}_{3}, \mathrm{Sb}_{2} \mathrm{O}_{3}, \mathrm{CoO}$ ou óxidos de terras-raras, e subsequentes etapas de conformação e sinterização típicas do processamento cerâmico. ${ }^{(3)} \bigcirc$ material resultante é uma cerâmica policristalina que apresenta uma singular propriedade de contorno de grão, na qual tem origem a conhecida relação não-linear característica do dispositivo e que é a base de sua utilização para proteção de sistemas e equipamentos elétricos. ${ }^{(1)}$

Do ponto de vista microestrutural, estes varistores são formados por grãos de $\mathrm{ZnO}$, semicondutor do tipo $\mathrm{n}$, envolvidos por camadas ou filmes intergranulares, idealmente extremamente finos ( $1-50 \mathrm{~nm}$ ), ou mesmo inexistentes, apresentando elevado grau de densificação. Diversos mecanismos de condução eletrônica foram propostos com base nesta microestrutura e, atualmente, do ponto de vista elétrico, interpreta-se a microestrutura destes dispositivos como sendo semelhante a uma rede de circuitos em série e em paralelo formada por homojunções entre grãos de $\mathrm{ZnO}$ e heterojunções constituídas entre os grãos de $\mathrm{ZnO}$ e as camadas intergranulares $(\mathrm{ClG}) .{ }^{(2)}$ Medições de capacitância em função da tensão aplicada têm dado suporte ao modelo da dupla barreira do tipo Schottky, localizadas nas vizinhanças dos contornos de grão, como explicação para a origem do comportamento elétrico não-linear (não ôhmico) do dispositivo. ${ }^{(1,2)}$

Desde o início da década de 1970 o conhecimento acerca dos varistores tem sido continuamente ampliado, o que tem se refletido na produção industrial destes componentes e proporcionado uma constante otimização de seus desempenhos elétricos. Contudo, as questões relacionadas ao comportamento da corrente de fuga e aos problemas de absorção de energia e dissipação de calor, conjuntamente referidas como estabilidade eletrotérmica, constituem-se no maior desafio da atual tecnologia de varistores. ${ }^{(1,4)}$ De fato, principalmente para aplicações em altas tensões, para proteção de linhas de transmissão e distribuição de energia elétrica, bem como em subestações de energia, onde os varistores são empregados sob a forma de blocos como componentes ativos de pára-raios, o nível de proteção e a confiabilidade dos varistores devem ser bastante elevados, de forma a se evitar falhas que podem acarretar em vultosos prejuízos aos sistemas elétricos e aos consumidores.

Dessa forma, a otimização do comportamento eletrotérmico do dispositivo tem sido perseguida mediante os desenvolvimentos que possibilitem a produção de microestruturas que apresentem elevada homogeneidade físico-química. Como se trata, essencialmente, de semicondutores compostos policristalinos, os estudos de dopagem têm sido muito considerados com o intuito de aperfeiçoar o comportamento elétrico dos varistores. Com este intuito, os trabalhos de Gupta ${ }^{(1,5)}$ mostraram que características microestruturais desejáveis podem ser maximizadas (o que tem sido chamado de Engenharia de Microestrutura) mediante a dopagem seletiva do $\mathrm{ZnO}$ com diversos dopantes que podem apresentar afinidades para localização nos grãos ou nos contornos de grão da microestrutura cerâmica. Gilbert et al. ${ }^{(6)}$ mostraram que as características semicondutoras de varistores à base de $\mathrm{ZnO}$ podem ser alteradas em função da concentração de um mesmo dopante, refletindo-se fortemente sobre o desempenho eletrotérmico do dispositivo. Assim, no sentido de aperfeiçoar ou avaliar o desempenho dos varistores, é de fundamental importância o conhecimento acerca de suas características microestruturais. Nesse contexto, o objetivo do presente trabalho é apresentar alguns resultados de avaliação microestrutural de cerâmicas varistoras efetuada com base em métodos de análise e processamento de imagens aplicadas a fotomicrografias obtidas por microscopia eletrônica de varredura.

\section{MATERIAIS E MÉTODOS}

As cerâmicas varistoras analisadas neste trabalho foram produzidas segundo o método cerâmico convencional. Os reagentes (P. A.) constituintes das formulações, após pesagem, passaram por moagem (24 h), com uso de álcool isopropílico para homogeneização da mistura e calcinação $\left(900^{\circ} \mathrm{C}, 3 \mathrm{~h}\right)$. O pó calcinado e cominuído passou por um processo de conformação através da prensagem uniaxial a seco da mistura em uma matriz de aço, sob pressão igual a $100 \mathrm{MPa}$ por 4 minutos. A quantidade de pó usada na conformação de cada pastilha foi de $(\mathrm{I}, 000 \pm 0,005) \mathrm{g}$. A sinterização $\left(1.350^{\circ} \mathrm{C}, 2 \mathrm{~h}\right)$ das pastilhas foi efetuada num forno tubular, com taxas de aquecimento e resfriamento, respectivamente, iguais a $5^{\circ} \mathrm{C}$ e $6^{\circ} \mathrm{C} / \mathrm{min}$, sob atmosfera de ar. As pastilhas obtidas (com, em média, 12,6 mm de diâmetro e I,6 mm de espessura) passaram por preparação ceramográfica e foram caracterizadas por microscopia eletrônica de varredura (MEV), espectroscopia de raios-X por dispersão de energia (EDS), difração de raios-X (DRX) e análises densimétricas em balança analítica para avaliar o grau de densificação das peças cerâmicas em relação à densidade teórica do $\mathrm{ZnO}$. Os procedimentos de análise de imagens foram implementados no programa Image-Pro Plus 6.0 (Media Cybernetics, 2006), empregando-se essencialmente ferramentas dos menus Enhance, Process e Measure. A composição química (em \% molar) das cerâmicas varistoras estudadas é dada por $(99,80-x) \cdot Z n O-x \cdot \mathrm{Me}_{x} \mathrm{O}_{y}-0,20 \cdot \mathrm{CoO}$, designado como ZTR, onde x é a porcentagem molar do óxido deterras-rarasutilizado (indicado por $\mathrm{Me}_{x} \mathrm{O}_{y}$; podendo ser $\operatorname{Pr}_{6} \mathrm{O}_{11}$ ou $\mathrm{Nd}_{2} \mathrm{O}_{3}$, ou ainda a mistura 
deles; no caso do presente trabalho). Comparativamente, amostras de cerâmicas varistoras convencionais, de composição química 96.5. $\mathrm{ZnO}-0.5 \cdot \mathrm{Bi}_{2} \mathrm{O}_{3}-1.0 \cdot \mathrm{Sb}_{2} \mathrm{O}_{3}-1 \cdot 0 \cdot \mathrm{CoO}-0.5 \cdot \mathrm{MnO}-0.5 \cdot \mathrm{Cr}_{2} \mathrm{O}_{3}$, designada como ZB, também foram avaliadas.

\section{RESULTADOS E DISCUSSÃO}

A Figura I mostra típicas características microestruturais de cerâmicas varistoras à base de $\mathrm{ZnO}$, que, idealmente, consiste principalmente de grãos semicondutores de $\mathrm{ZnO}$, apresentando contornos de grão bem definidos, tal como as homojunções grão-grão mostradas na Figura Ib. Contudo, as microestruturas reais, comumente produzidas por sinterização em presença de fase líquida, como a mostrada na Figura la, exibem considerável formação de camadas intergranulares e fases secundárias precipitadas, em função da composição química utilizada. Idealmente, as CIG devem apresentar espessuras bastante estreitas em microestruturas com elevado grau de densificação (baixa porosidade) de forma a minimizar a corrente de fuga. ${ }^{(2,3)}$ De fato, as microestruturas com elevada densificação, tais como aquelas mostradas nas Figuras Ia, Ic, 2b e 2c, proporcionam a formação de homojunções nos contornos de grão, Figuras $2 b$ e 2 c, que se comportam como "micro-varistores", apresentando um comportamento elétrico não-linear em escala microscópica. ${ }^{(1,2)}$ Em oposição, a Figura $2 a$ mostra a formação de CIG com uma considerável distribuição heterogênea, que geralmente está associada à degenerescência do comportamento eletrotérmico. ${ }^{(1,4)}$

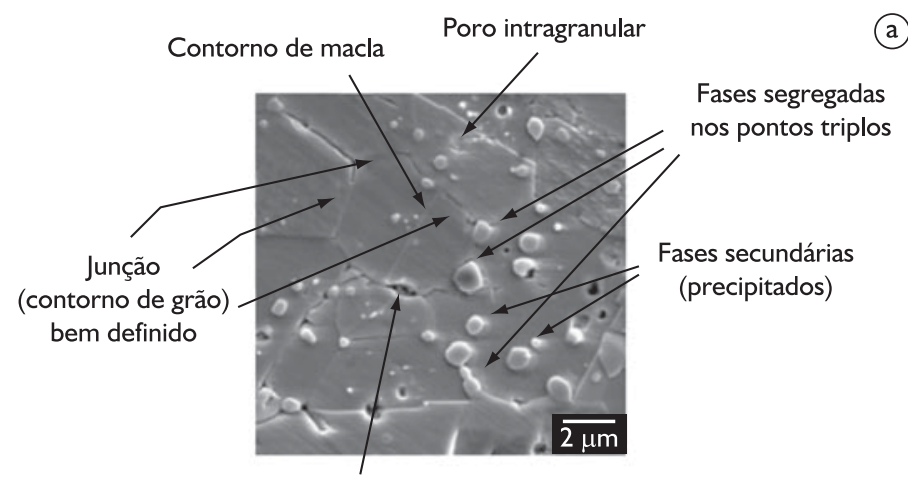

Poro intergranular

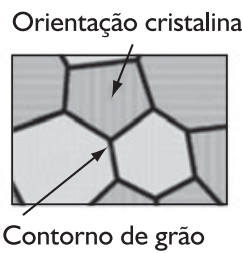

(b)

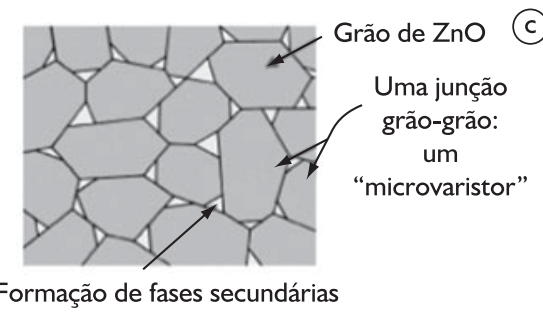

Figura I. a) Características microestruturais típicas de cerâmicas varistoras à base de $\mathrm{ZnO}$; b) representação esquemática da orientação cristalina e contornos de grão ideais; c) esquema simplificado da microestrutura real de um varistor.
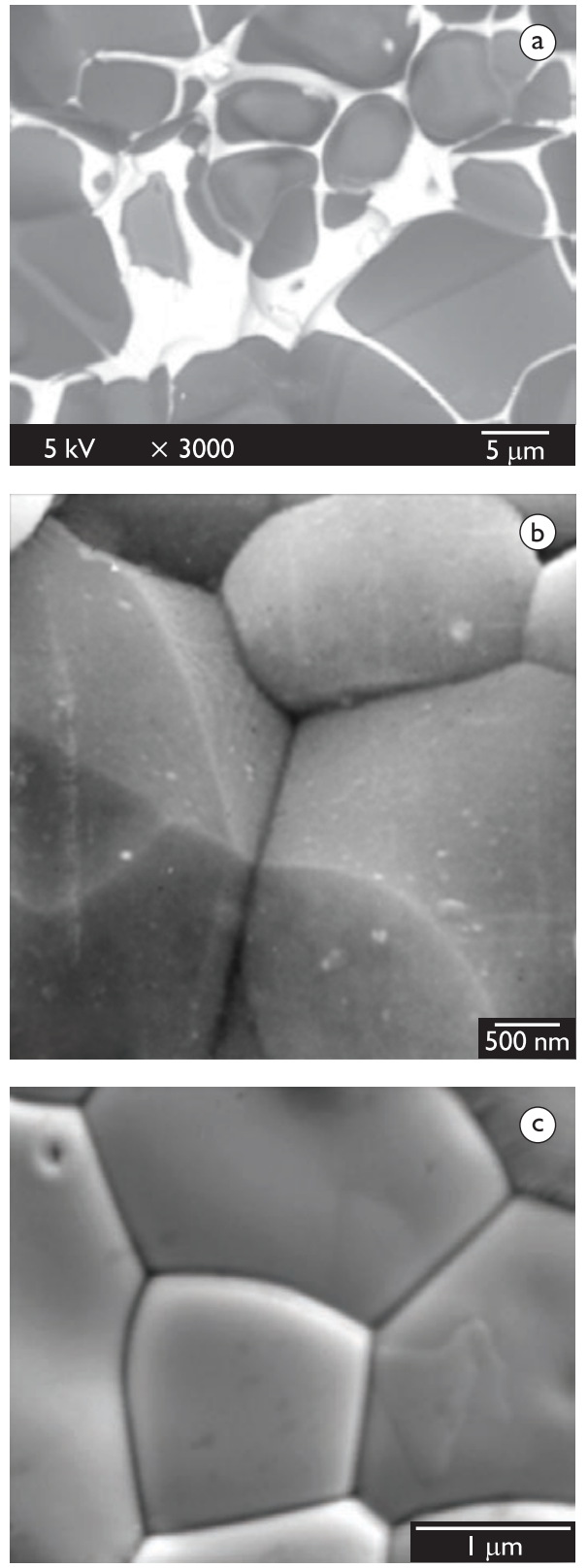

Figura 2. a) Formação irregular e heterogênea (cluster) de camadas intergranulares; b) grãos de $\mathrm{ZnO}$ em contato direto (homojunções); c) exemplo de microestrutura com elevada densificação e alta homogeneidade físico-química, sem formação de camadas intergranulares nítidas.

Neste sentido, as Figuras 3a e 3b mostram comparativamente exemplos de microestrutura das cerâmicas varistoras ZTR e ZB, onde a primeira apresenta um aspecto mais denso e com maior homogeneidade físico-química em relação a segunda. Adicionalmente, as Figuras $3 c$ e $3 d$ mostram os difratogramas obtidos por difração de raios-X dos sistemas ZTR (apresentando somente as fases $\mathrm{ZnO}$ e rica em terras-raras) e $\mathrm{ZB}$ (evidenciando a estrutura multifásica, incluindo espinélio e fases ricas em bismuto). 

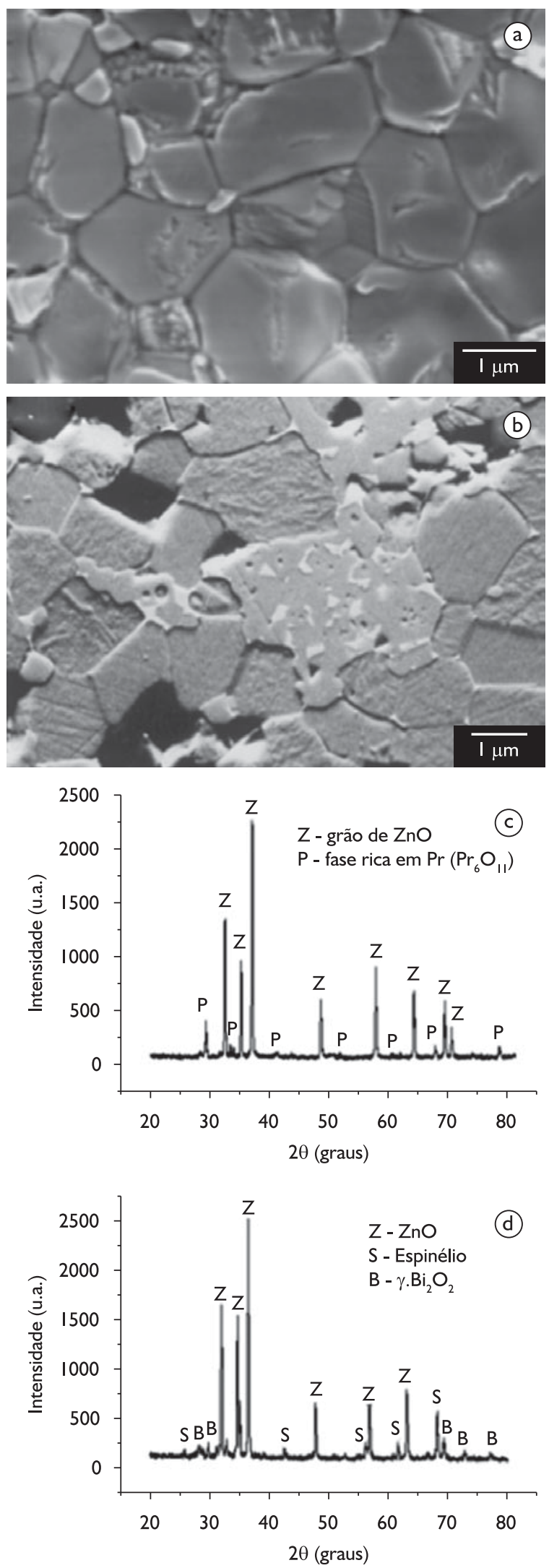

Figura 3. Características microestruturais das cerâmicas varistoras estudadas: Fotomicrografias (MEV) características das cerâmicas a) ZTR; b) ZB. Resultados de análise por difração de raios- $X$ dos sistemas cerâmicos segundo as formulações: c) ZTR; d) ZB.
Embora microestruturas com elevado grau de densificação e nítidos contornos de grão, sem aparente $\mathrm{CIG}$, como aquelas mostradas nas Figuras $2 b$ e $2 c$ possam ser obtidas, o exame mais detalhado pode evidenciar a formação de ClG extremamente delgadas, remanescentes da sinterização por fase líquida. Este é o caso das fotomicrografias apresentadas na Figura 4, pois na Figura 4b, o tratamento da imagem da Figura 4a permitiu a identificação do filme nanométrico na região de contorno de grão marcada com "Z". Os resultados de EDS apresentados na Figura 4 mostram que o cobalto é um dopante anfótero, pois pode ser encontrado tanto no seio do grão de $\mathrm{ZnO}$ quanto na região de contornos de grão. De fato, as CIG mais espessas, tal como a marcada com "Y" na Figura 4a, resultam da retração não-homogênea da fase líquida a partir das elevadas temperaturas de sinterização ao longo do resfriamento do corpo cerâmico.
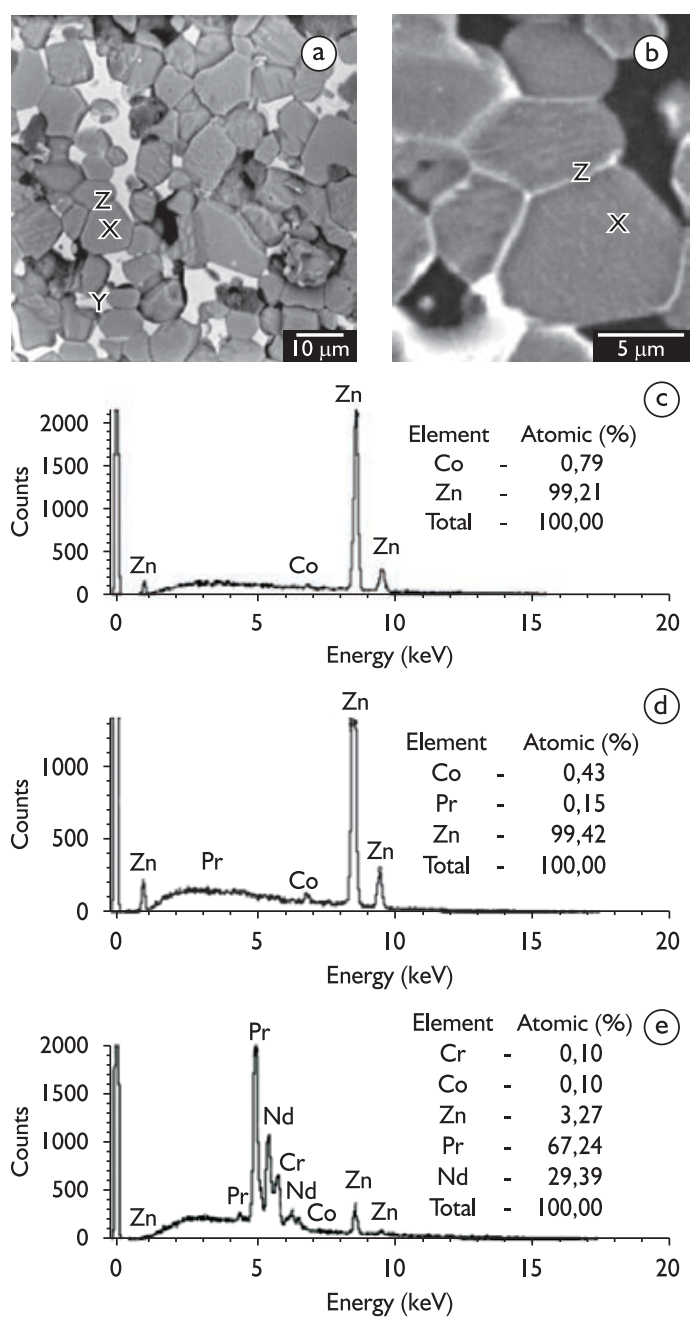

Figura 4. a) Fotomicrografia da superfície polida a atacada do sistema cerâmico ZTR; b) detalhes das regiões marcadas com X e Z. Resultados de análise EDS: c) seio do grão de $\mathrm{ZnO}$ (ponto X), d) contorno de grão ideal (ponto Z); e) região da camada intergranular (ponto $Y$ da Figura 4a). 
O levantamento dos principais parâmetros que caracterizam a microestrutura de uma cerâmica varistora e condicionam o seu desempenho elétrico pode se beneficiar sobremaneira com o uso de procedimentos e técnicas de processamento e análise de imagens. A Figura 5 mostra três fotomicrografias obtidas por MEV e as respectivas sequências de processamento de imagem, através do uso de filtros e procedimentos de segmentação, que evidenciam características microestruturais específicas (neste caso, principalmente tamanho de grão e grau de densificação). A partir das imagens binarizadas pode-se determinar tamanhos e distribuição de tamanhos de grão, perímetros e curvaturas de contornos de grão, conforme exemplificado nas imagens apresentadas na Figura 6. Num outro trabalho, a partir do uso destes resultados, foi possível relacionar estes parâmetros microestruturais com a capacidade de absorção de energia destas cerâmicas varistoras. ${ }^{(4)}$
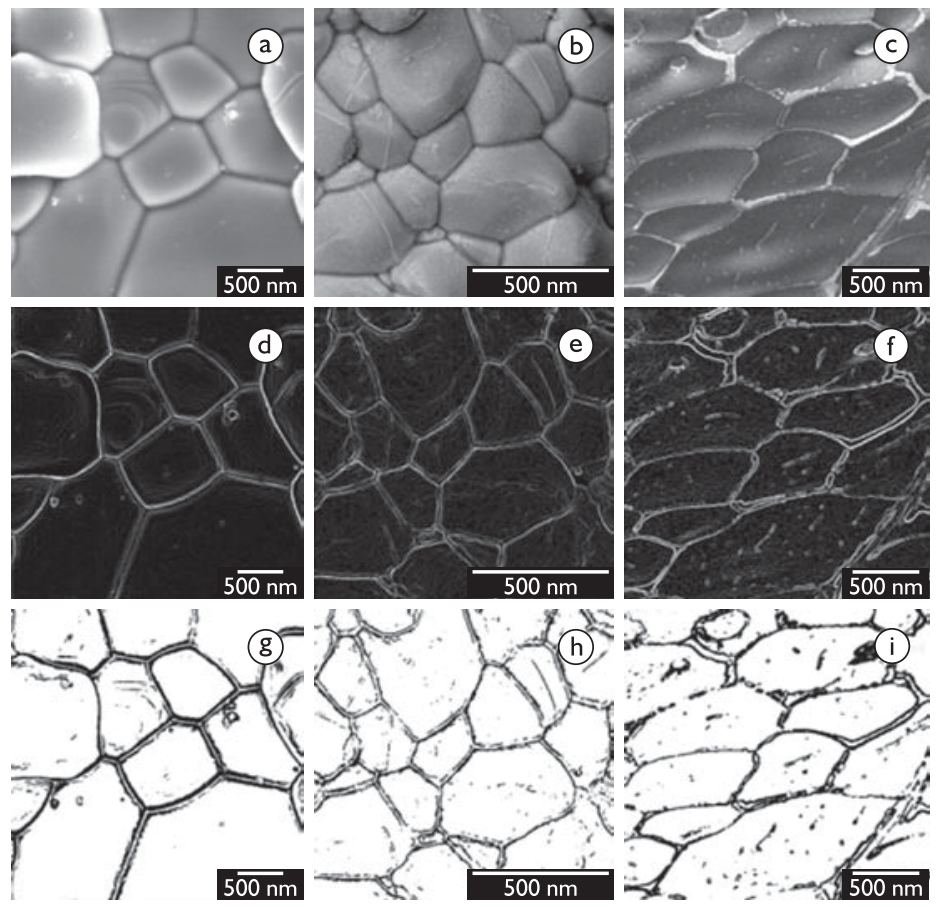

Figura 5. Fotomicrografias de microestruturas com elevada densificação e respectivos processos de análise de imagens: a), b) e c) cerâmicas ZTR com diversos teores de terras-raras; d), e) e f) uso de filtro mediana e Sobel para detecção de fronteiras; g), h), i) após processamento de segmentação e binarização (menu Process do programa empregado e controle de nitidez).

Outro exemplo de aplicação de análise de imagens é apresentado na Figura 7, onde a partir da fotomicrografia original obtida por MEV, Figura 7a, utilizando-se métodos de diferenciação, segmentação, binarização e pseudocores ${ }^{(8)}$ foi possível identificar as fases secundárias presentes na microestrutura, enumerando-se estas regiões, Figura 7b, - que resultou na construção da máscara de imagem apresentada na Figura 7c. A partir deste resultado, procedimentos dinâmicos permitem individuar os elementos da máscara e agrupá-los, Figura 7d, proporcionando a formação de uma estrutura equivalente ao conjunto das fases secundárias e a quantificação da área total ocupada por estas fases, Figura 7e, em relação à área do fotomicrografia original. Este procedimento também permite quantificar porosidade e pode ser

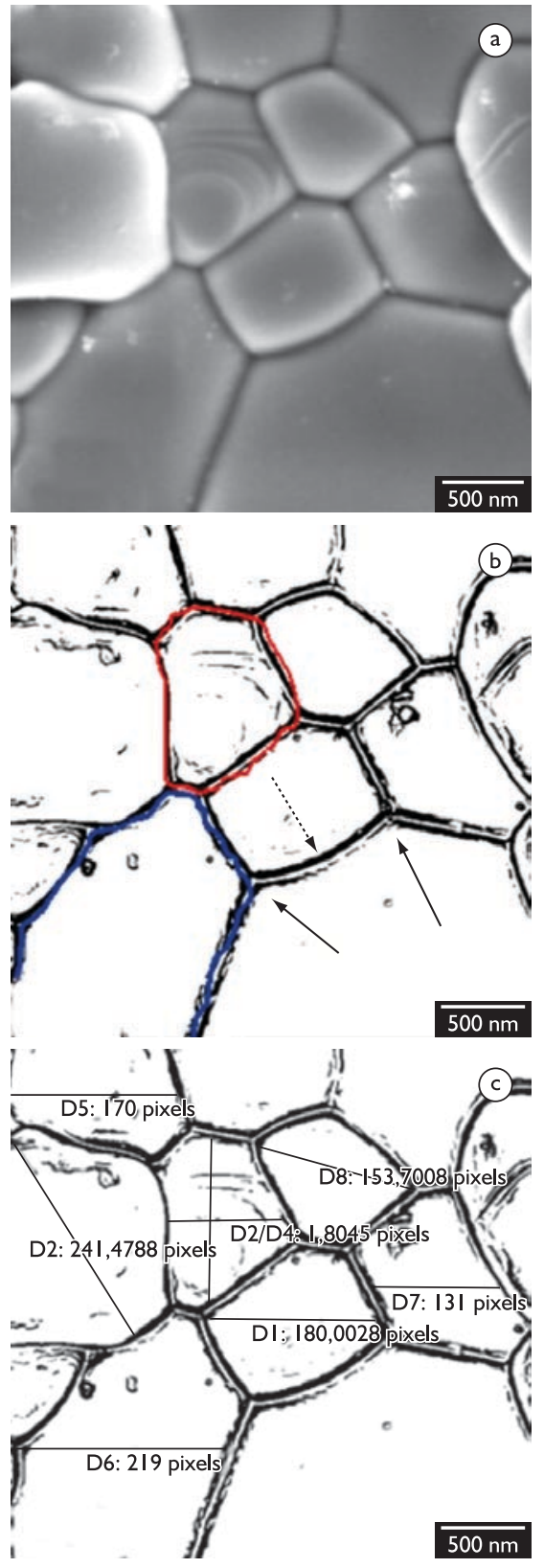

Figura 6. a) Fotomicrografia original de cerâmica ZTR; b) medições de características de contornos de grão após o processamento de segmentação e binarização; c) medições de tamanho e orientação de grãos (menu Measure do programa empregado) sobre a fotomicrografia binarizada (e calibrada).

automatizado, com a implementação de rotinas macros, proporcionando a avaliação de diversas fotomicrografias de um determinado corpo cerâmico. Os resultados deste processo podem ser conjugados com outras informações provenientes ou não da análise de imagens, proporcionando a obtenção de relações tais como aquelas apresentadas na Figura 8, onde as características microestruturais são apresentadas em função do teor de óxidos de terras-raras (formadores de CIG) utilizado. 


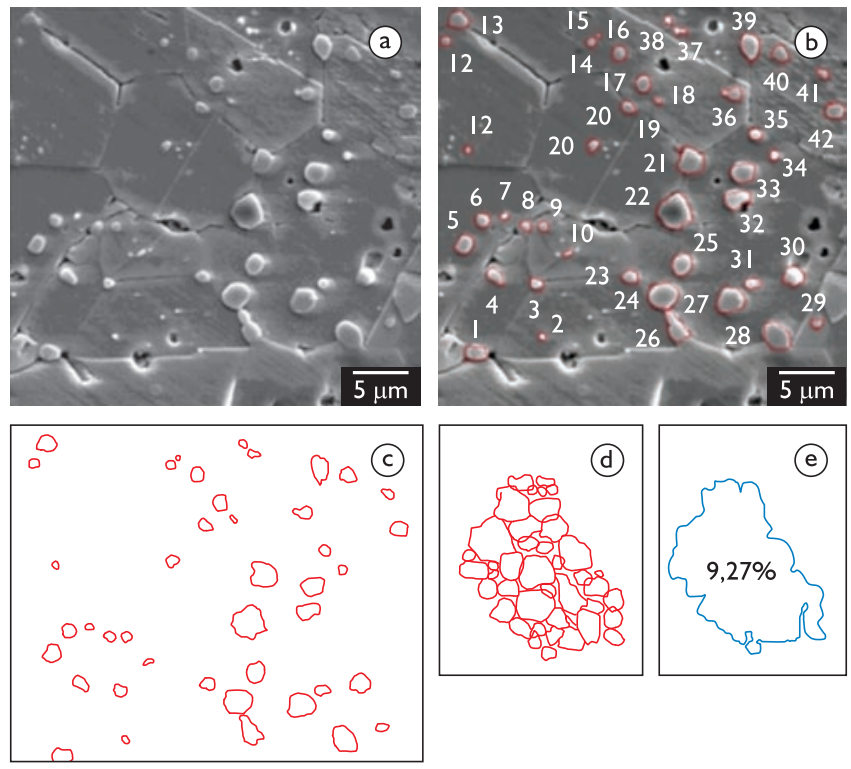

Figura 7. Resultados da caracterização microestrutural utilizando técnicas de análise de imagens: a) fotomicrografia original; b) identificação de fases secundárias; c) máscara de imagem da imagem original apresentado as fases secundárias isoladas; d) agrupamento e quantificação de áreas.

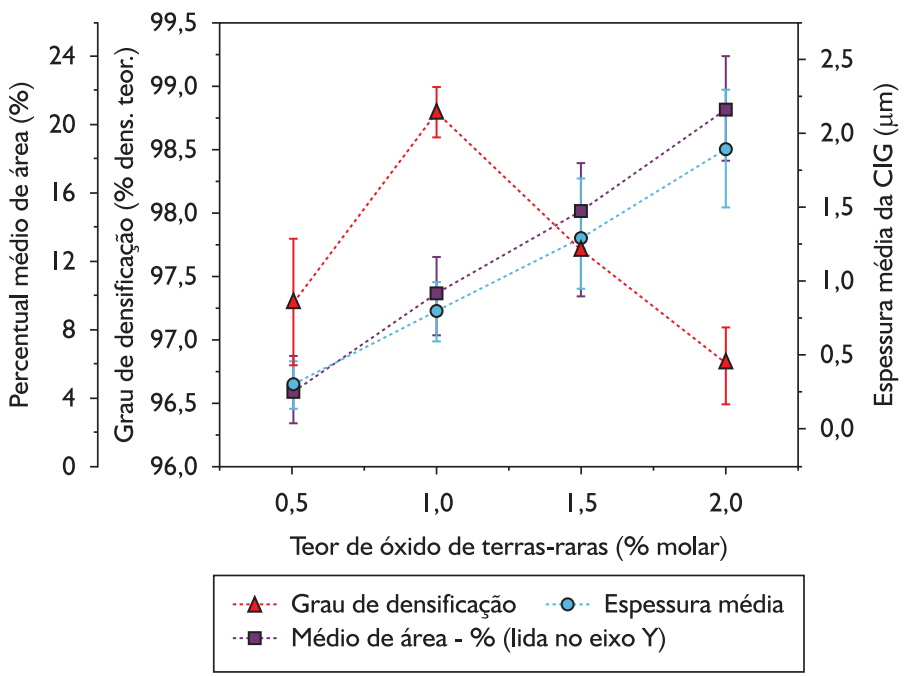

Figura 8. Características microestruturais (grau de densificação, espessura média das camadas intergranulares e percentual médio de área das fotomicrografias ocupado por fases secundárias) em função do teor de óxidos de terrasraras (em \% molar) utilizado $\left(50 \% \operatorname{Pr}_{6} \mathrm{O}_{11}+50 \% \mathrm{Nd}_{2} \mathrm{O}_{3}\right)$.

Dessa forma, com base nos resultados apresentados na Figura 8 e na caracterização elétrica apresenta em outros trabalhos, ${ }^{(4,7,9)}$ nota-se claramente que os parâmetros que caracterizaram o melhor desempenho elétrico, obtidos com I,0\% molar de óxido de terras-raras, estão diretamente relacionados ao maior grau de densificação alcançado. Adicionalmente, as relações entre a espessura média das CIG - obtida para um total de dez medições com base em fotomicrografias dos sistemas considerados -, o percentual médio de área de uma fotomicrografia ocupado por CIG e precipitados de terras-raras (excetuando-se porosidades) - também obtido com base nas medições em fotomicrografias, como acima considerado -, e o teor de óxido de terras-raras são lineares e crescem fortemente com o aumento deste teor.

\section{CONCLUSÃO}

No presente trabalho foram consideradas e exemplificadas algumas técnicas de processamento e análise de imagens aplicadas ao entendimento das características microestruturais de cerâmicas varistoras. Processos de diferenciação, segmentação e binarização foram empregados com o intuito de automatizar procedimentos de determinação de tamanho de grão, perímetro de contornos de grão, identificação de fases secundárias e porosidades. Com base nestes procedimentos foi apresentado um estudo acerca da influência do teor de material formador de camadas intergranulares sobre o grau de densificação, a espessura média das camadas intergranulares e o percentual médio de área das fotomicrografias ocupado por fases secundárias, proporcionando parâmetros e conhecimentos para uma otimização microestrutural.

\section{REFERÊNCIAS}

I GUPTA, T. K. Application of zinc oxide varistors. Journal of the American Ceramic Society, v. 73, n. 7, p. 1817-40, 1990.

2 CLARKE, D. R. Varistor ceramics. Journal of the American Ceramic Society, v. 82, n. 3, p. 485-502, 1999.

3 LAGRANGE, A. Present and future of zinc oxide varistors. In: STEELE, B. C. H. (Org.) Electronic ceramics. Londres: Elsevier Applied Science, 199I p. I-27.

4 FURTADO, J. G. M., et al. Relações empíricas entre características microestruturais e absorção de energia em cerâmicas varistoras. Tecnologia em Metalurgia e Materiais, v. 4, n. 3, p. I-6, jan.-mar. 2008

5 GUPTA, T. K. Microstructural engineering through donor and acceptor doping in the grain and grain boundary of a polycrystalline semiconducting ceramic. Journal of Materials Research, v. 7, n. 12, p. 3280-95, Dec. 1992.

6 GILBERT, I.; FREER, R. Donor and acceptor doping of zinc oxide varistors. Journal of Physics: Condensed Matter, v. I4, p. 945-54, 2002.

7 FURTADO, J. G. M., et al. Microstructural evaluation of rare-earth-zinc oxide-based varistor ceramics. Materials Research, v. 8, n. 4, p. 425-9, 2005.

8 ARNOULD, X.; COSTER, M.; CHERMANT, J - L. Segmentation and grain size of ceramics. Image Analysis \& Stereology, v. 20, p. I3I-5, $200 \mathrm{I}$.

9 FURTADO, J. G. M., et al. An image analysis study on varistor ceramic microstructures correlated to their electrothermal performances. In: CONGRESSO ANUAL DA ABM, 63., 2008, Santos. Anais... São Paulo: ABM, 2008. p. 508-18.

Recebido em: 12/04/2009

Aceito em: 7/04/2010 